\title{
Effects of orienting instructions on sensitivity to scheduled contingencies
}

\author{
RICHARD J. DEGRANDPRE, WILLIAM BUSKIST, and DAVID CUSH \\ Auburn University, Auburn, Alabama
}

\begin{abstract}
Orienting instructions acquaint subjects with the experimental task and apparatus. Although orienting instructions are a common feature of operant research, their behavioral effects have not been extensively investigated. In the present study, each of four groups received a different set of orienting instructions prior to responding on a multiple fixed-interval, fixed-ratio schedule of reinforcement. Subjects who received the most detailed instructions, which specified the task and the response manipulandum, and in which subjects were advised to earn as many points as possible, showed the least amount of response variability, but they also showed the least sensitivity to programmed contingencies. Subjects that received the same instructions, minus the advice to maximize points, showed less between-subject variability than did the remaining two groups, and greater discrimination between schedule components than did all other groups. Subjects who received instructions that did not specify the task or response manipulandum showed considerable variability in responding and less sensitivity to programmed contingencies. Although orienting instructions may be required for subjects to contact the experimental contingencies, some orienting instructions influence subjects' sensitivity to the experimental contingencies more than others.
\end{abstract}

In the experimental analysis of human behavior, instructions are typically used for two reasons: to orient subjects to the apparatus and task (i.e., orienting instructions), and to specify experimental contingencies (i.e., contingency-specifying instructions). Although effects of the latter on behavior have been investigated in some detail (for a review, see Baron \& Galizio, 1983), the effects of the former have been examined only rarely (e.g., see Terrell, Bennett, Buskist, \& Williams, 1986). Furthermore, although the effects of contingency-specifying instructions have been addressed, the effects of such instructions have typically not been separated from possible effects of orienting instructions per se, thus providing a possible methodological confound.

In one study of the effects of orienting instructions (Terrell et al., 1986), four groups of subjects received different orienting instructions prior to being exposed to a fixedinterval (FI) schedule of reinforcement. Orienting instructions differentially affected response rates of subjects across each of the groups. Subjects in the group that was told to "earn as many points as possible" (maximum instructions) responded at the highest rates, and the group that received minimal instructions (no mention of the experimental task or apparatus) responded at the lowest rates. Terrell et al. concluded that orienting instructions may interact with contingency-specifying instructions to control human performance in operant contexts. Unfortunately, Terrell et al. did not examine the effects of orienting instructions on subjects' sensitivities to sched-

Requests for reprints may be addressed to Richard J. DeGrandpre or William Buskist, Psychology Department, Auburn University, Auburn, AL 36849-5214. uled contingencies across different schedules of reinforcement. Although tests of subjects' sensitivities in responding have been the primary focus of the research on contingency-specifying instructions mentioned above, the effects of orienting instructions on subjects' sensitivities to scheduled contingencies have not been examined.

In the present study, we investigated the effects of orienting instructions on subjects' sensitivity in responding under a multiple fixed-interval, fixed-ratio (FI FR) reinforcement schedule. The multiple FI FR schedule was used because sensitive or differential responding would be demonstrated as lower rates under the FI component relative to higher rates under the FR component.

\section{METHOD}

\section{Subjects}

Twenty Auburn University undergraduate students, 14 males and 6 females, participated. The subjects received class credit in their introductory psychology course. Extra credit was dependent on participation only and not on any qualitative aspect of performance. No subjects reported any prior experience with behavioral research.

\begin{abstract}
Apparatus
The subjects were seated before an IBM PC with a monochrome monitor, in one of three Industrial Acoustics Company sound-attenuating chambers. Two of the chambers were identical in size $(198 \times 183 \times$ $163 \mathrm{~cm})$, while the third was larger $(198 \times 213 \times 258 \mathrm{~cm})$. A hard plastic Tandy keyboard cover, modified such that only the keyboard's space bar was accessible, was placed over the keyboard. The PC and keyboard in each chamber sat on a $74 \mathrm{~cm}$ high table.

The PC was programmed to deliver points upon the completion of either the FI or the FR component of a multiple schedule. The FI component was signaled by the letter " $A$ " in the top left corner of the monitor; the FR component was signaled by the letter " $B$ "' in the top right corner of the monitor. Each letter was enclosed in a box that simultaneously appeared on the screen with the letter. When points were deli-
\end{abstract}


vered, the words "DO NOT RESPOND" appeared simultaneously in the lower left corner of the screen for $3 \mathrm{sec}$. Points earned appeared in a box that remained at the lower center of the screen.

\section{Procedure}

The subjects were assigned randomly to one of four groups and told not to discuss the details of the experiment with other individuals during or following their participation. Depending on the group to which they were assigned, the subjects were read one of the following sets of instructions prior to each 20 -min session.

1. Operant level (Group 1):

Please remain in this booth until I return for you or until the message on the monitor instructs you to call the experimenter. You can do anything you like but please stay in the booth. Please do not ask any further questions. Do not remove the keyboard cover.

2. Orienting instructions without a lever description (Group 2):

By depressing the space bar you may begin the session. When the session is over you will be told to call the experimenter. When this mes- sage appears you may exit the booth. Every time you receive points they will appear on the screen. These points will be added to any other points you have earned. By depressing the space bar you may begin the session. Please do not ask any further questions.

3. Orienting instructions with lever description (Group 3); these instructions were identical to the instructions in (2) above, except for two additional sentences:

By depressing the space bar you may earn points on a counter. Every press, however, will not always result in accumulating points on the counter.

4. Orienting instructions with a statement to maximize point earnings (Group 4); these instructions were identical to the instructions in (3) above, except for two additional sentences:

Your task is to earn as many points as possible. Let me repeat, as many points as possible.

Any questions asked by a subject were responded to by rereading the

\section{GROUP 1}
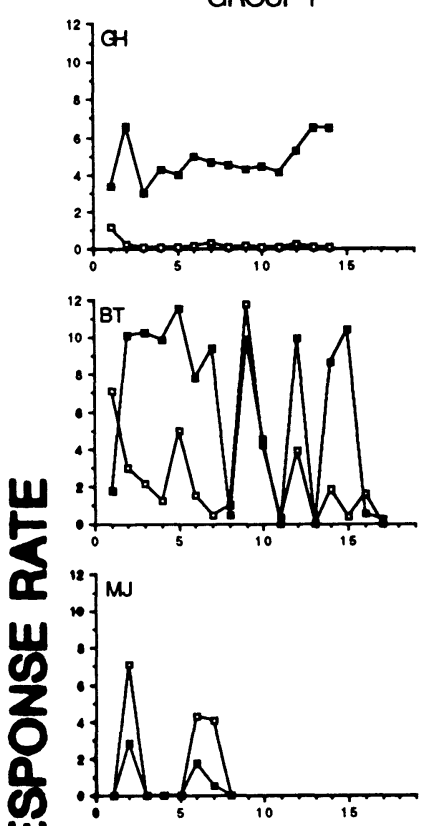

12
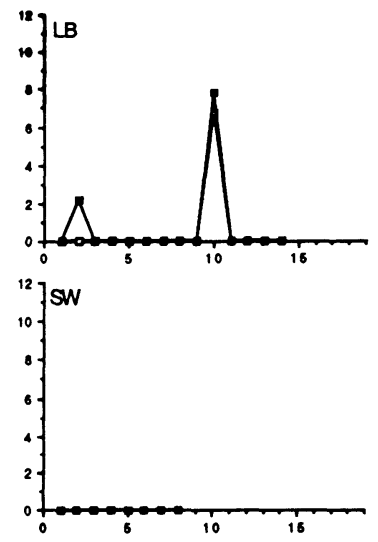

GROUP 2
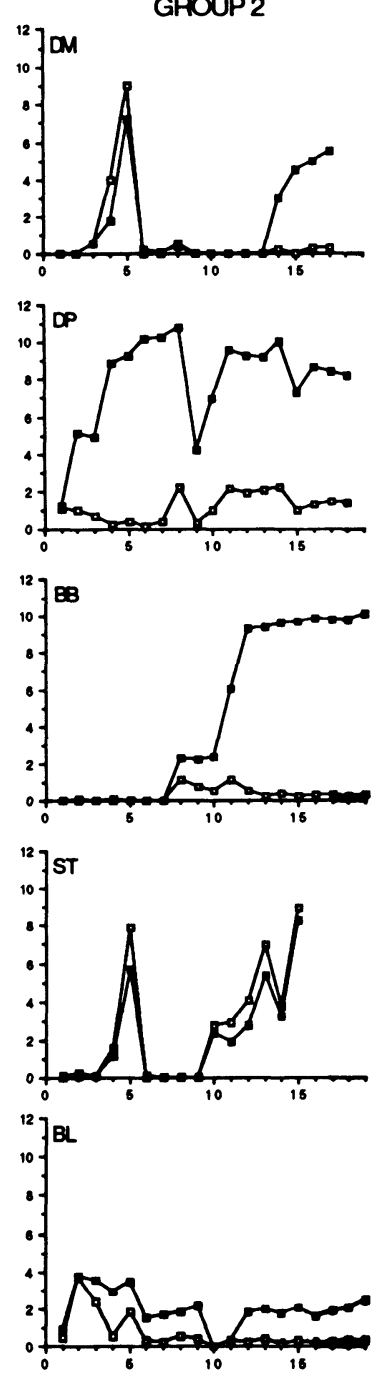

GROUP 3
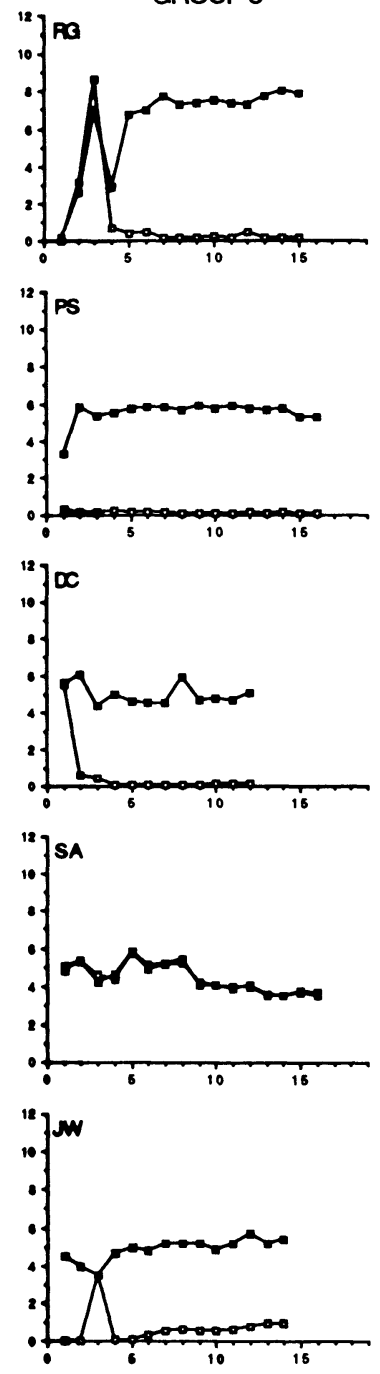

GROUP 4
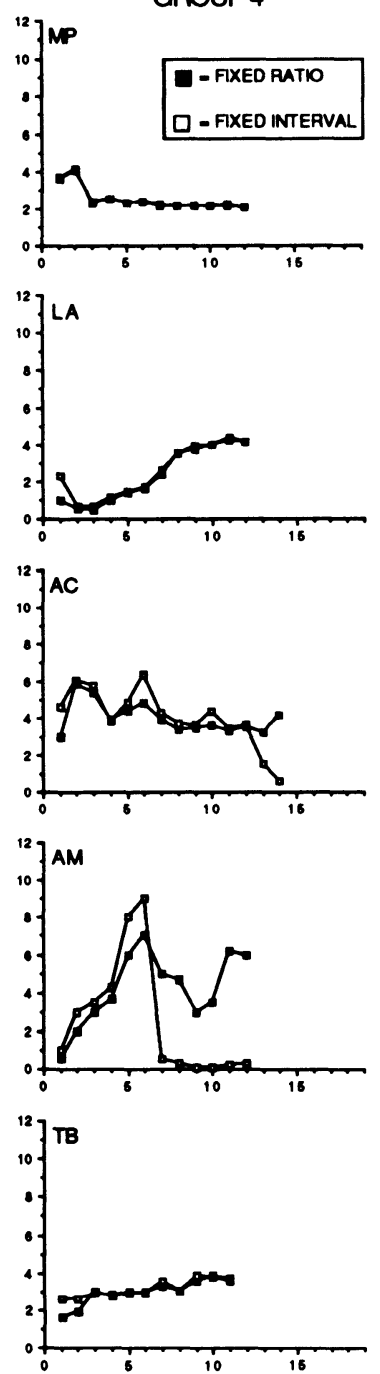

\section{SESSION}

Figure 1. Individual performances of subjects in each group. Response rates for each component of the multiple schedule are plotted by session. Circles represent response rates under the FR component; triangles represent response rates under the FI component. 
appropriate portion of the instructions, or by stating, "All the information that is available is printed on the screen."

Space bar presses produced 25 points according to a multiple FI 20 , FR 60 reinforcement schedule. Which component was in effect was determined randomly by the computer program. The subjects completed a minimum of eight sessions during their participation in the experiment. The number of sessions completed by subjects varied according to how many sessions (one or two) a subject completed each day (3 subjects, S.W., L.B., and M.J., either did not respond, or had response latencies that caused them to complete only one session for that day) and the total number of sessions required for responding to stabilize.

\section{RESULTS}

Figure 1 shows the individual performances of subjects in each group. Response rates for each component of the multiple schedule are plotted by session. The subjects' responding was considered to be discriminated when the response rate for the FR component was twice that of the FI schedule. According to this criterion, discriminated responding varied widely across groups. Only 1 subject (G.H.) in Group 1 showed discrimination, with an FR rate of about five responses per second and an FI response rate of less than one per second. Four out of 5 subjects in both Group 2 and Group 3 showed clear discrimination between the FR and FI components. Only 2 subjects (A.C. and A.M.) in Group 4 showed discriminated responding.

As Table 1 shows, subjects in Group 3 tended to show discriminated responding before subjects in the other groups. Table 1 also shows individual discrimination indices (calculated by dividing the FR response rate by the FI response rate) for subjects in each group over the last four sessions in the experiment. A discrimination index of 1 indicates no discrimination between schedule components; the larger the value, the greater the FR response

Table 1

Number of Sessions to Stable Discriminated Responding and Discrimination Indices (DI) for Individual Subjects in the Experiment

\begin{tabular}{clcr}
\multicolumn{2}{c}{ Discrimination Indice (DI) for Individual Subjects in the Experiment } \\
\hline Group & Subject & Sessions & \multicolumn{1}{c}{ DI } \\
\hline 1 & G.H. & 1 & 36.36 \\
& B.T. & & 3.89 \\
& M.J. & & .37 \\
& L.B. & & \\
& S.W. & & \\
& D.M. & 14 & 24.21 \\
& D.P. & 2 & 6.27 \\
& B.B. & 9 & 36.56 \\
& S.T. & & .83 \\
& B.L. & 12 & 7.77 \\
& R.G. & 4 & 32.17 \\
& P.S. & 1 & 49.82 \\
& D.C. & 3 & 39.83 \\
& S.A. & & .96 \\
& J.W. & 4 & 7.58 \\
& M.P. & & 1.00 \\
& L.A. & & 1.02 \\
& A.C. & & 1.54 \\
& A.M. & 6 & 18.80 \\
& T.B. & & 1.00 \\
\hline
\end{tabular}

rate relative to the FI response rate. An index lower than 1 indicates a higher rate of responding in the FI component relative to the FR component. Discrimination indices for Group 3 are generally higher and more consistent across subjects than for the other three groups.

In general, the subjects in Groups 1 and 2 showed more within-subject variability in responding than did the subjects in Groups 3 and 4. Three of the 5 subjects in Group 1 frequently emitted no or only a few responses per session. The subjects in all other groups showed larger amounts of responding in both schedule components. Within components of the multiple schedule, Group 3 subjects showed the most stable rates of responding.

\section{DISCUSSION}

The orienting instructions used in the present study were representative of those used in previous studies. For example, Catania, Matthews, and Shimoff (1982) instructed subjects on the contextual stimuli and the type of response to be emitted (cf. Groups 3 and 4 in the present study). Harzem, Lowe, and Bagshaw (1978) and Shimoff, Catania, and Matthews (1981) instructed subjects to maximize reinforcement (e.g., "your goal is to earn as many points as you can"; cf. Group 4). Other researchers have stated the experimental task explicitly (cf. Group 4), including contingency-specifying instructions (e.g., Perone \& Baron, 1980; Poppen, 1982).

The results of the present experiment can be summarized as follows: Subjects who received orienting instructions, including a description of the response to be performed but without the instruction to maximize point earnings (Group 3), showed clearer, quicker, and more consistent response discrimination than did subjects receiving any other type of orienting instructions (Groups 1, 2, and 4). Group 3 subjects also showed the least amount of variability in responding between and within schedule components.

These results suggest three recommendations for the use of orienting instructions in human operant research. First, some degree of orienting instructions appears necessary to bring subjects' behavior into consistent contact with the experimental contingencies. Second, the use of orienting instructions which specify that subjects should earn as many points as possible as well as respond maximally is likely to prevent responding from becoming sensitive to critical aspects of the experimental contingencies. Instructions to maximize reinforcement should not be used in human operant experiments in which discriminated responding is the dependent variable of interest. Third, orienting instructions that appear to engender discriminated responding quickly and consistently between and within subjects are those that include a brief description of the operant response as well as a description of the apparatus. Orienting instructions that do not include a description of the operant response will engender discriminated responding, although not as quickly or with the same degree of stability as orienting instructions that include such description of the operant response.

On the basis of the results of the present experiment, we recommend orienting instructions such as those given to Group $\mathbf{3}$ for use in human operant research that requires discriminated responding. This sort of orienting instruction appears sufficient to bring responding into contact with experimental contingencies without interfering with those contingencies.

The present results clearly show that orienting instructions can influence human behavior in operant contexts. Such findings suggest that human operant researchers ought to consider the effects of orienting instructions when designing their research. In a review of 188 human operant studies published in the Journal of the Experimental Analysis of Behavior, Pilgrim and Johnston (1988) concluded that reporting of either orienting or contingency-specifying instructions has not been a standard practice. Pilgrim and Johnston warn that even subtle differences in the wording of instructions may have strong effects on subjects' performances, and they "question whether reseachers always place 
sufficient importance on the instructional design." Our results support Pilgrim and Johnston's concern and underscore the importance of attending carefully to instructional protocol in designing and conducting human operant research.

\section{REFERENCES}

Baron, A., \& Galizio, M. (1983). Instructional control of human operant behavior. Psychological Record, 33, 495-520.

Catania, A. C., Matthews, B. A., \& Shimoff, E. (1982). Instructed versus human verbal behavior: Interactions with nonverbal responding. Journal of the Experimental Analysis of Behavior, 38, 233-248.

Harzem, R., Lowe, C. F., \& Bagshaw, M. (1978). Verbal control in human operant behavior. Psychological Record, 28, 405-423.

Perone, M., \& Baron, A. (1983). Reinforcement of human observing behavior by a stimulus correlated with extinction or increased effort. Journal of the Experimental Analysis of Behavior, 34, 239-261.
Pilgrim, C., \& Johnston, J. M. (1988). Laboratory lore and research practices in the experimental analysis of behavior: Issues in instructing subjects. Behavior Analyst, 11, 59-64.

POPPEN, R. (1982). Human fixed-interval performance with concurrently programmed schedules: A parametric analysis. Journal of the Experimental Analysis of Behavior, 37, 251-266.

Shimoff, E., Catania, A. C., \& Matthews, B. A. (1981). Uninstructed human responding: Sensitivity of low-rate performance to schedule contingencies. Journal of the Experimental Analysis of Behavior, 36, 207-220.

Terrell, D. J., Bennett, R. H., Buskist, W., \& Williams, R. A. (1986). Effects of orienting instructions on human fixed-interval performance. Bulletin of the Psychonomic Society, 24, 107-109.

(Manuscript received November 15, 1989.) 